\title{
Effects of Soaking Aqueous Ammonia Pretreatment on Selected Properties and Enzymatic Hydrolysis of Poplar (Populus trichocarpa) Wood
}

\author{
Florentyna Akus-Szylberg,* Andrzej Antczak, and Janusz Zawadzki \\ Effects of soaking aqueous ammonia pretreatment were considered for \\ fast-growing poplar wood in the context of bioethanol production. The \\ milled Populus trichocarpa wood with a particle size of 0.43 to $1.02 \mathrm{~mm}$ \\ was pretreated at two temperatures $\left(50{ }^{\circ} \mathrm{C}\right.$ and $\left.90{ }^{\circ} \mathrm{C}\right)$ and two \\ concentrations of ammonia solution ( $15 \%$ and $20 \% \mathrm{w} / \mathrm{w})$ for $20 \mathrm{~h}$. The \\ lignin content decreased by $46 \%$ in the biomass treated with the most \\ severe conditions. After enzymatic hydrolysis, the sugar yield was \\ analysed, and the results indicated that increased temperature and \\ ammonia concentration during pretreatment resulted in higher glucose \\ content. Additionally, changes in the degree of polymerization and \\ available pore volume were investigated.
}

Keywords: Poplar; Soaking aqueous ammonia; Enzymatic hydrolysis; Bioethanol

Contact information: Department of Wood Science and Wood Preservation, Institute of Wood Sciences and Furniture, Warsaw University of Life Sciences - SGGW, 159 Nowoursynowska St., 02-776 Warsaw,

Poland; *Corresponding author: florentyna_akus_szylberg@sggw.edu.pl

\section{INTRODUCTION}

Due to environmental, economic, and energy factors, as well as the spread of governmental policies restricting the exploitation of traditional hydro-carbon fuels, fossil fuel driven energy is in transition to renewable and green options. Enzymatically based ethanol from lignocellulosic biomass is a remarkable example of a bio-energy product. Currently, among liquid biofuels, ethanol has the largest market due to its use as a chemical feedstock, fuel additive, or primary fuel (Kerr and Service 2005). The enzymatic hydrolysis that converts lignocellulosic biomass to fermentable sugars is the most complex step in bioethanol procurement due to the natural recalcitrance of plant cell walls (Yang et al. 2011). The chemical components of wood are strongly intermeshed and bonded with lignin forming the lignocellulosic matrix, which is resistant to hydrolytic enzymes. Thus, the efficient utilization of lignocellulosic feedstock for bioethanol production requires an appropriate pretreatment as a necessary upstream process to increase polysaccharides susceptibility to enzyme digestion, which is achieved by breaking the ligninhemicelluloses barrier (Chundawat et al. 2011).

The soaking aqueous ammonia (SAA) process is a chemical pretreatment that has been praised as a remarkable delignification method. Alkali pretreatment alters the initial structure of the biomass by both swelling cellulose and solubilizing lignin and hemicelluloses, which results in the exposure of cellulose to enzymes. Generally, hemicelluloses are much more susceptible to chemical reactions in alkaline medium than cellulose. At elevated temperatures during the SAA treatment the most important reactions with polysaccharides that occur are: dissolution of under graded polysaccharides; peeling 
of end-groups and the formation of alkali stable end-groups; alkaline hydrolysis of glycosidic bonds and acetyl groups; and degradation and decomposition of dissolved polysaccharides and peeled monosaccharides. The reactions of peeling and hydrolysis are the main cause of losses of polysaccharides during treatment and decreases in the degree of polymerization (Fengel and Wegener 1984; Balan et al. 2012). Furthermore, during the peeling reactions the reducing end groups of carbohydrates are eliminated, and different carboxylic acid compounds are formed, some of which are enzymatic inhibitors such as acetic acid and formic acid (Geng et al. 2018). Additionally, aromatic acids or phenolic compounds, which also can have inhibitory effect on enzymes, may be formed as a result of lignin degradation during alkali pretreatment. The notable advantage of the SAA method is that ammonia used in the pretreatment may be recycled from the effluent and reused (Gao et al. 2016). However, the long treatment time, high concentration of the base, and formation of residual salts in biomass are some of the flaws of alkali treatment (Verardi et al. 2012). Nonetheless, the course and outcomes of the reactions with alkali depends only on substrate-related factors and on applied pretreatment conditions: the alkali concentration, temperature, and time.

Choosing an appropriate method and conditions for the pretreatment of a particular biomass is critical for efficient ethanol production. As the suitability of a feedstock for bioconversion depends on its chemical composition and structure, the objective of this study was to investigate the effect of applying different conditions of the alkali treatment on the particular so far unresearched in this context fast-growing Populus trichocarpa wood intended for bioethanol production via enzymatic hydrolysis. Changes in chemical composition of the treated biomass were investigated as the primary criterion when designating the pathway for its conversion. The final assessment of the SAA treatment conditions was based on its subsequent enzymatic hydrolysis yield. The degree of cellulose polymerization was examined as another important factor indicating a suitable pretreatment. In addition, the available pore volume was studied with an innovative inverse size-exclusion chromatography method.

\section{EXPERIMENTAL}

\section{Materials}

This study was performed on a stem-wood of the fast-growing poplar (Populus trichocarpa) obtained from a field owned by the Institute of Biology, Department of Genetics, Plant Breeding and Biotechnology at Warsaw University of Life Sciences, Poland. The 7-year-old poplar was harvested, debarked, air-dried, chipped, and milled into particles with dimensions of 0.43 to $1.02 \mathrm{~mm}$. Cellic CTec2 (Novozymes, Bagsvaerd, Denmark), which is a mixture of cellulases, $\beta$-glucosidases, and hemicellulases with a density of $1.203 \mathrm{~g} / \mathrm{cm}^{3}$, was used as a catalyst for hydrolysis. Chemicals used in these studies were of analytical grade and purchased from Chempur (Piekary Śląskie, Poland) unless stated otherwise.

\section{Methods}

SAA pretreatment

The intended fraction of raw material (biomass with $7 \%$ moisture content was used in a quantity equal to circa $20 \mathrm{~g}$ of an absolutely dried material) was placed in a stainlesssteel reactor with the capacity of $250 \mathrm{~mL}$, and either $15 \%$ or $20 \%$ (w/w) ammonia solution 
was added in order to apply a solid:liquid ratio of 1:12.5. The pretreatment conditions were based on previous research and selected for their preferable delignification ability (Gao et al. 2016). The reactor was placed in oil bath that was pre-set and subsequently maintained at $50{ }^{\circ} \mathrm{C}$ or $90{ }^{\circ} \mathrm{C}$ for $20 \mathrm{~h}$ after the load inside the reactor reached the set temperature, and then it was cooled rapidly. The solid and liquid fractions were separated by filtration. Two experiments were carried out at each given condition, and the two obtained water-washed solid fractions were mixed.

\section{Chemical composition analysis}

Both untreated wood and treated solid fractions were subjected to chemical composition analysis. The extractives content was determined following the procedure by Antczak et al. (2006). The Kürschner-Hoffer method (Saeman et al. 1954; Krutul 2002) was performed for cellulose isolation and content determination. The total lignin content (Klason lignin and acid soluble lignin) was determined according to TAPPI T222 om-02 (2006) and TAPPI UM 250 (1985). Holocellulose content was examined according to the sodium chlorite method described by Wise et al. (1946). Each sample was analysed in triplicates, and single standard deviations were calculated.

\section{Enzymatic hydrolysis}

The 72-h enzymatic hydrolysis was performed for both untreated and treated biomass in triplicates for each material. The Cellic CTec2 enzyme with the activity of 151 FPU/mL measured with Whatman No.1 filter paper according to the National Renewable Energy Laboratory (NREL) method was used (Adney and Baker 1996). The hydrolysis process and high-performance liquid chromatography (HPLC) analysis of glucose and xylose content in the hydrolysates were performed according to the procedures described by Antczak et al. (2018) and Akus-Szylberg et al. (2020a).

\section{Size exclusion chromatography}

Size exclusion chromatography (SEC) was used to analyse a weight average polymerization degree $\left(D P_{\mathrm{w}}\right)$ and polydispersity index $(D P I)$ of cellulose samples before and after SAA pretreatment. The cellulose was isolated by Kürschner-Hoffer method and dissolved following the procedure by Antczak et al. (2016). Afterward, the prepared samples were submitted to the SEC analysis and then processed according to Waliszewska et al. (2018). However, the HPLC system included a different column filled with crosslinked polystyrene-divinylbenzene gel (PLgel, $10 \mu \mathrm{m}$, MIXED-B, 7.5×300 mm) connected to the guard column (PLgel, $10 \mu \mathrm{m}$ GUARD, $7.5 \times 50 \mathrm{~mm}$ ).

The column calibration was performed with a set of polystyrene standards (Agilent Technologies, Palo Alto, USA) with molar masses from 6570000 to 9570 Da dissolved in $0.5 \% \mathrm{LiCl} / \mathrm{DMAc}$ were used. The molar mass $(M)$ of cellulose was calculated by MarkHouwink universal calibration (Eq. 1),

$$
[\eta]=K \times M \alpha
$$

where $[\eta]$ is intrinsic viscosity $(\mathrm{mL} / \mathrm{g}), M$ is molar mass $(\mathrm{Da})$, and $K(\mathrm{~mL} / \mathrm{g})$ and $\alpha$ are parameters that depend on a polymer type, solvent, and temperature. For a polystyrene $K$ $=17.35 \times 10^{-3} \mathrm{~mL} / \mathrm{g}$ and $\alpha=0.642$ (Timpa 1991), and for the cellulose $K=2.78 \times 10^{-3}$ $\mathrm{mL} / \mathrm{g}$ and $\alpha=0.957$ (Bikova and Treimanis 2002). Finally, the $D P_{\mathrm{w}}$ and the DPI of cellulose were determined as described by Waliszewska et al. (2018). 


\section{Inverse size-exclusion chromatography}

The porosity of both untreated and SAA-treated samples was examined using an inverse size-exclusion chromatography (ISEC) and HPLC system according to the procedure described by Akus-Szyberg et al. (2020b). To determine the volume of pores in the samples, analytic standards chosen according to Radomski (2015) dissolved in the redistilled water were passed through a column: a set of ten dextran standards (Fluka, Everett, USA), a set of three poly(oxyethylene) standards (Polymer Standards Service, Mainz, Germany), maltose, glucose (both POCh, Gliwice, Poland), ethylene glycol (SigmaAldrich, Taufkirchen, Germany), and methanol. Molar mass $(M)$ at the peak maximum of the listed above standards ranged from 32 to $401300 \mathrm{~g} / \mathrm{mol}$, and the viscosity radius $\left(r_{\eta}\right)$ was defined as follows (Striegiel et al. 2009),

$$
r_{\eta}=\left(3[\eta] M / 10 \pi N_{A}\right)^{1 / 3}
$$

where $N_{A}$ is Avogadro's constant. The available specific volume of pores $V_{p}$ was calculated according to the pores distribution function developed by Radomski (2015) based on the retention time corresponding to the peak apex of the particular standard.

\section{RESULTS AND DISCUSSION}

\section{Effect of SAA Pretreatment on the Chemical Composition of Poplar Wood}

The SAA treatment changed the chemical composition of the poplar biomass notably, as shown in Table 1. Generally, the hemicelluloses content of the treated biomass was much lower than that of the untreated sample, which accounted also for the decrease in holocellulose content. However, increased ammonia concentration during alkali treatment had a limited effect on hemicelluloses, while raising the temperature of the process influenced their degradation more visibly. The hemicelluloses content in samples treated with SAA method at $50{ }^{\circ} \mathrm{C}$ both with the $15 \%$ and $20 \%$ ammonia solutions was approximately $68 \%$ lower than in case of native poplar biomass, while for the material treated with $90{ }^{\circ} \mathrm{C}$ it was $74.4 \%$ and $75.3 \%$ lower, respectively. In other studies considering different lignocellulosic biomass from corn stover pretreated with the SAA carried out at $60{ }^{\circ} \mathrm{C}$ and at $15 \%$ ammonia solution, much more limited solubility (only $17.2 \%$ ) of hemicelluloses was reported (Kim et al. 2008).

Proportional cellulose content in any treated biomass was prominently higher than in untreated feedstock. However, that apparent increase was caused by general mass loss during treatment as a result of hemicelluloses loss and lignin deterioration (Fengel and Wegener 1984). The highest cellulose proportion was achieved in the biomass treated at the most severe conditions, and it was $32.9 \%$ higher than in the untreated feedstock. Kordala et al. (2013) reported very similar findings, stating $32.5 \%$ higher cellulose proportion in Miscanthus giganteus biomass after the SAA performed at $15 \%$ of ammonia concentration and at $80^{\circ} \mathrm{C}$. Likewise, Zhu et al. (2019) who studied Robinia pseudoacacia described $32.5 \%$ higher cellulose proportion in the material treated with the SAA $(21 \%$ of $\mathrm{NH}_{3} ; 70^{\circ} \mathrm{C}$ ) than in the control sample.

The SAA in this experiment proved very effective in removing lignin only at higher concentrations of ammonia. After increasing the concentration of the alkali up to $20 \%$ during pretreatment, the lignin in biomass treated with $50{ }^{\circ} \mathrm{C}$ and $90{ }^{\circ} \mathrm{C}$ was $40 \%$ and $46 \%$ lower, respectively, than in the raw material. At $21 \%$ of ammonia concentration, Zhu et al. (2019) noted delignification of $25 \%$ for treated black locust wood biomass. In this study, 
in the milder alkali environment $\left(15 \%\right.$ of $\left.\mathrm{NH}_{3}\right)$, the lignin content stayed roughly the same as in untreated biomass despite changes in the applied temperature. However, in another study performed on poplar biomass, $15 \%$ delignification was detected after treatment with higher alkali concentration $\left(30 \% \mathrm{NH}_{3}\right.$ ), but at ambient temperature (Himmelsbach 2009).

In all the SAA-treated samples, the extractives content was at least half lower than in untreated biomass, except for material after most severe treatment, in which higher content of extractives might have been effect of condensing lignin and carbohydrate degradation products. Those products might had been detected as extractives, as reported by Akus-Szylberg et al. (2020a), who subjected poplar biomass to liquid hot water (LHW) pretreatment.

Table 1. Chemical Composition of Untreated and SAA-Pretreated Poplar Wood

\begin{tabular}{|c|c|c|c|c|c|}
\hline \multirow{5}{*}{$\begin{array}{c}\text { Component } \\
(\%)\end{array}$} & \multicolumn{5}{|c|}{ Poplar Wood } \\
\hline & \multirow{4}{*}{ Untreated } & \multicolumn{4}{|c|}{ Ammonia Concentration (\%) } \\
\hline & & \multicolumn{2}{|c|}{15} & \multicolumn{2}{|c|}{20} \\
\hline & & \multicolumn{4}{|c|}{ SAA Pretreatment Temperature $\left({ }^{\circ} \mathrm{C}\right)$} \\
\hline & & 50 & 90 & 50 & 90 \\
\hline Extractives & $1.7 \pm 0.1$ & $0.8 \pm 0.1$ & $0.7 \pm 0.2$ & $0.8 \pm 0.1$ & $1.7 \pm 0.1$ \\
\hline Cellulose & $50.2 \pm 0.4$ & $64.8 \pm 0.2$ & $66.1 \pm 0.9$ & $65.5 \pm 0.6$ & $66.7 \pm 0.1$ \\
\hline Holocellulose & $85.4 \pm 0.6$ & $76.1 \pm 0.9$ & $75.6 \pm 0.2$ & $76.9 \pm 0.2$ & $75.4 \pm 0.6$ \\
\hline Hemicelluloses* & 35.2 & 11.3 & 9.5 & 11.4 & 8.7 \\
\hline Lignin & $20.0 \pm 0.2$ & $20.1 \pm 0.3$ & $20.3 \pm 0.2$ & $12.1 \pm 0.2$ & $10.8 \pm 0.4$ \\
\hline Mass loss & - & 9.0 & 10.2 & 13.1 & 17.7 \\
\hline
\end{tabular}

\section{Glucose and Xylose Content}

As shown in Fig. 1, the SAA process increased the amount of glucose and xylose obtained from enzymatic hydrolysis compared with the sugars content from raw poplar wood (6\%). Cumulative sugars content after saccharification of treated biomass ranged from $39.6 \%$ to $44.1 \%$ with minor variability between samples. However, in the same biomass after the LHW pretreatment, sugar yield reached more than $50.0 \%$ after hydrolysis (Akus-Szylberg et al. 2020a), which confirms that the SAA process is more effective on agricultural residues than on wood materials in terms of hydrolysis efficiency (Kumar and Wyman 2009). Nonetheless, in the poplar biomass obtained after the LHW treatment, lignin content stayed roughly the same as in the raw material, while over $90 \%$ hemicelluloses were solubilized, contrary to the SAA method, in which much less polysaccharides were degraded.

Glucose content in the treated biomass grew along with increasing temperature of the process and also an increase in ammonia concentration, however only at the higher temperature. The highest glucose content was obtained from lignocellulosic material treated with the SAA at $90{ }^{\circ} \mathrm{C}$ and at $20 \%$ of ammonia solution; the xylose content was the lowest in that biomass. In all cases, pretreatment increased the xylose content compared with untreated feedstock (1.6\%). The highest average xylose content $(13.3 \%)$ was obtained at $50{ }^{\circ} \mathrm{C}$ and at $20 \%$ of $\mathrm{NH}_{3}$, which seems to correspond with the results of holocellulose and hemicelluloses contents (Table 1). Geng et al. (2018) reported 7.3\% glucose recovery for untreated poplar after enzymatic hydrolysis, in contrast to $48.8 \%$ of glucose recovery for cellulose-rich residues obtained after alkaline extraction from raw material.

The results suggest that hemicelluloses provided the key barrier to initial cellulose breakdown by enzymes and its degradation significantly improves the enzymatic 
hydrolysis compared with raw biomass. There is a direct relationship between xylan extraction and glucose yield (Ishizawa et al. 2007). With the removal of hemicelluloses, the accessible surface area of cellulose increases, which improves the enzymatic conversion. Lignin is also a major barrier for enzymatic hydrolysis, and its removal usually improves the yield of the hydrolysis (Geng et al. 2018).

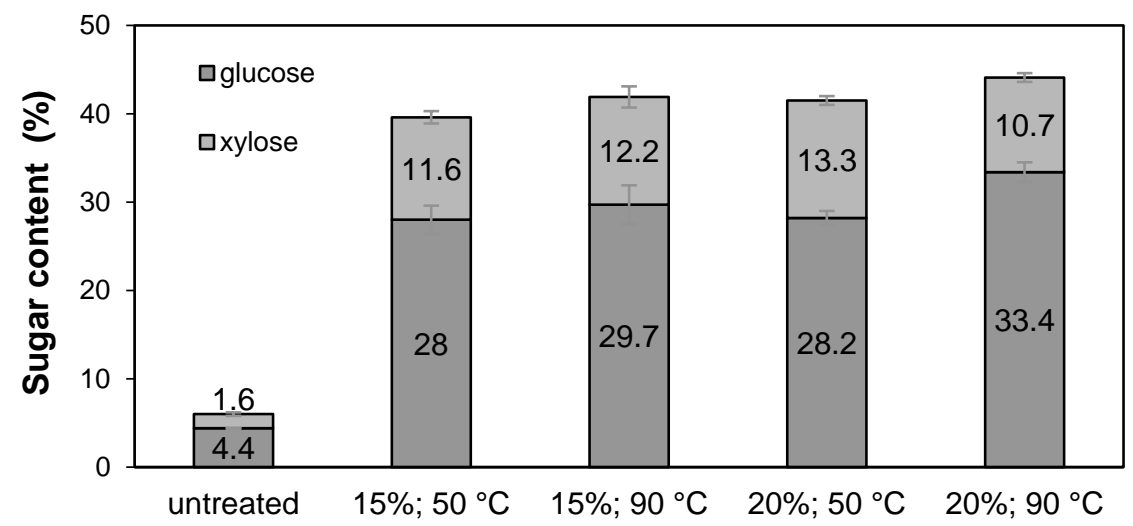

Fig. 1. The sugars content (glucose and xylose) after enzymatic hydrolysis of Populus trichocarpa both untreated and treated with SAA process

Table 2. The Number Average Molar Mass $\left(M_{\mathrm{n}}\right)$, Weight Average Molar Mass $\left(M_{\mathrm{w}}\right), D P I$ and $D P_{\mathrm{w}}$ of Cellulose in Untreated and SAA Pretreated Poplar Wood

\begin{tabular}{|c|c|c|c|c|c|}
\hline $\begin{array}{c}\text { Ammonia } \\
\text { concen. } \\
(\%)\end{array}$ & $\begin{array}{c}\text { Temp. } \\
\left({ }^{\circ} \mathrm{C}\right)\end{array}$ & $M_{n}$ & $M_{w}$ & DPI & DPw \\
\hline \multicolumn{2}{|c|}{ Untreated } & $27802.0 \pm 9010.4$ & $259020.0 \pm 9475.1$ & $10.4 \pm 4.0$ & $1598.9 \pm 58.5$ \\
\hline \multirow{2}{*}{15} & 50 & $21293.3 \pm 1275.6$ & $200900.0 \pm 1852.0$ & $9.5 \pm 0.5$ & $1240.1 \pm 11.4$ \\
\cline { 2 - 6 } & 90 & $20706.7 \pm 1260.8$ & $173066.7 \pm 14533.2$ & $8.4 \pm 0.3$ & $1068.3 \pm 89.7$ \\
\hline \multirow{2}{*}{20} & 50 & $21703.3 \pm 578.8$ & $191666.7 \pm 3635.0$ & $8.8 \pm 0.1$ & $1183.1 \pm 22.4$ \\
\cline { 2 - 6 } & 90 & $21150.0 \pm 406.3$ & $164866.7 \pm 11232.3$ & $7.8 \pm 0.4$ & $1017.7 \pm 69.3$ \\
\hline
\end{tabular}

\section{SEC Analysis}

The average values of polymerization degree and the polydispersity index of cellulose were lower in any pretreated biomass than in raw material, as shown in Table 2. The $D P_{\mathrm{w}}$ of cellulose from untreated and the SAA pretreated biomass ranged from approximately 1200 to 1600 . Li et al. (2017), who subjected poplar biomass to LHW method, reported the $D P$ w range of 1000 to 3000 and reduction in DPI after pretreatment from 11.4 to 8.5, very similar as in this study in which DPI decreased from 10.4 to 7.8. With increased temperature of SAA, the $D P_{\mathrm{w}}$ decline of $14 \%$ was observed for treatment at $15 \%$ and $20 \%$ of $\mathrm{NH}_{3}$. Changes in the ammonia concentration, while maintaining the same temperature, caused smaller $D P_{\mathrm{w}}$ decline. Shortening the cellulose chains should improve hydrolysis yield by making more ends available to the enzymes, but even a high reduction in $D P_{\mathrm{w}}$ in the alkali pretreated material has an inconsequential effect on the final hydrolysis yield (Yang et al. 2011). 


\section{ISEC Analysis}

The ISEC analysis (Fig. 2) revealed changes in the available specific pore volume in the biomass after the SAA treatment with the most notable development of the porous structure in the biomass pretreated with $20 \%$ of $\mathrm{NH}_{3}$ at $90{ }^{\circ} \mathrm{C}$. Considering the changes in the porous structure of the biomass that can enhance the enzymatic hydrolysis yield, the macropores are of the biggest concern. Pores larger than $10 \mathrm{~nm}$ facilitate the accessibility of the enzymes, which have radius of approximately $5 \mathrm{~nm}$, such as cellulase from Trichoderma reesei (Chundawat et al. 2011). In case of a native poplar wood average $V_{\mathrm{p}}$ of $0.9 \mathrm{~cm}^{3} / \mathrm{g}$ was detected and the smallest pores $(<0.5 \mathrm{~nm})$ were the most numerous. Szadkowski and Szadkowska (2020), who also studied Populus trichocarpa, reported 1.9 $\mathrm{cm}^{3} / \mathrm{g}$ as pore volume in the raw cellulose masses obtained from alkaline treatment. The cumulative $V_{\mathrm{p}}$ increased along with severity of the applied pretreatment conditions and after applying $20 \%$ of $\mathrm{NH}_{3}$ and $90{ }^{\circ} \mathrm{C}$ the biggest pores $(>5 \mathrm{~nm})$ volume more than doubled compared with raw biomass.

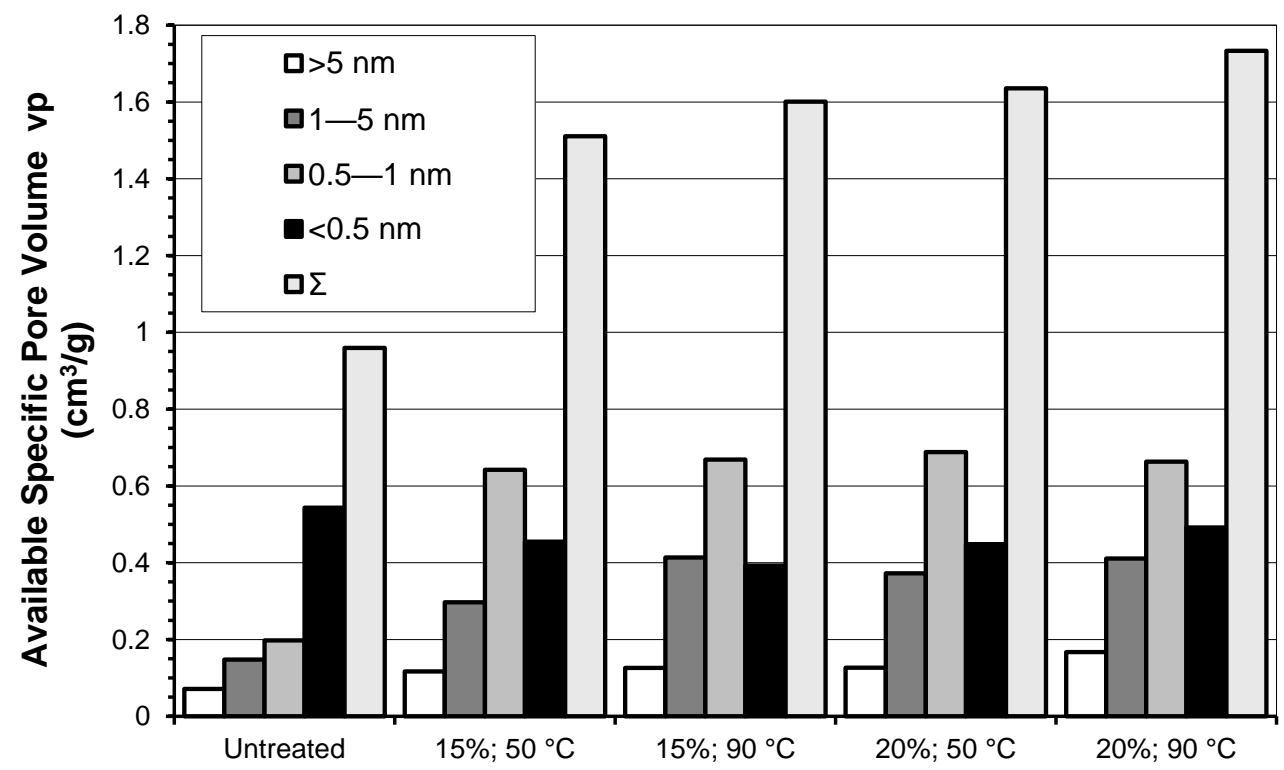

Fig. 2. Changes in the available specific volume of pores in poplar wood before and after the SAA pretreatment within the selected ranges of the standards radius

There are conflicting reports on pretreatment effectiveness and the extent of subsequent cellulose hydrolysis associated with the accessible pore volume and the surface area of the treated biomass (Ishizawa et al. 2007; Yang et al. 2011).

\section{CONCLUSIONS}

1. Poplar wood treated with SAA using $20 \%$ ammonia solution at 50 and $90{ }^{\circ} \mathrm{C}$ was successfully delignified, such that the lignin content was $40 \%$ and $46 \%$ lower, respectively, than in untreated feedstock.

2. The pretreatment increased both glucose and xylose yield after hydrolysis, with the glucose content improving along with increased process temperature and ammonia concentration. However, biomass pretreated at $15 \%$ of ammonia concentration showed 
very similar cumulative glucose and xylose conversion yield.

3. The soaking aqueous ammonia treatment decreased the degree of polymerization of the cellulose and increasing the temperature of the process was also influential. Moreover, the SAA method increased the available volume of pores in the biomass. The process performed at $90{ }^{\circ} \mathrm{C}$ and at higher ammonia concentration resulted in the formation of large pores, which seem decisive considering the subsequent hydrolysis process.

\section{ACKNOWLEDGMENTS}

This work was financed by a research project from the National Centre for Research and Development, which was "Intelligent systems for breeding and cultivation of wheat, maize, and poplar for optimized biomass production, biofuels, and modified wood" (BIOSTRATEG2/298241/10/NCBR/2016). Poplar material used in presented work was obtained in Welcome 2008/1 project of the Foundation for Polish Science given to Prof. Stanisław Karpiński.

\section{REFERENCES CITED}

Adney, B., and Baker, J. (1996). Measurement of Cellulase Activities (NREL/TP-51042628), National Renewable Energy Laboratory, Golden, CO.

Akus-Szylberg, F., Antczak, A., and Zawadzki, J. (2020a). "Hydrothermal pretreatment of poplar (Populus trichocarpa) wood and its impact on chemical composition and enzymatic hydrolysis yield," Drewno 63, 5-18.

Akus-Szylberg, F., Antczak, A., and Zawadzki, J. (2020b). "Changes in poplar (Populus trichocarpa) wood porous structure after liquid hot water (LHW) pretreatment," Annals of WULS - SGGW, Forestry and Wood Technology (accepted for publication)

Antczak, A., Radomski, A., and Zawadzki, J. (2006). "Benzene substitution in wood analysis," Annals of WULS - SGGW, Forestry and Wood Technology 58, 15-19.

Antczak, A., Radomski, A., Drożdżek, M., Zawadzki, J., and Zielenkiewicz, T. (2016). "Thermal ageing of cellulose with natural and synthetic antioxidants under various conditions," Drewno 59, 139-152.

Antczak, A., Marchwicka, M., Szadkowski, J., Drożdżek, M., Gawron, J., Radomski, A., and Zawadzki, J. (2018). "Sugars yield obtained after acid and enzymatic hydrolysis of fast-growing poplar wood species," BioResources 13, 8629-8645. DOI: 10.15376/biores.13.4.8629-8645

Balan, V., Da Costa Sousa, L., Chundawat, S. P., Humpula, J., and Dale, B. E. (2012). "Overview to ammonia pretreatments for lignocellulosic biorefineries," Dyn. Biochem. Process Biotechnol. Mol. Biol. 6(2), 1-11.

Bikova, T., and Treimanis, A. (2002). "Problems of the MMD analysis of cellulose by SEC using DMA/LiCl: A review," Carbohydrate Polymers 48(1), 23-28. DOI: 10.1016/S0144-8617(01)00207-7

Chundawat, S. P., Donohoe, B. S., Da Costa Sousa, L., Elder, T., Agarwal, U. P., Lu, F., Ralph, J., Himmel, M. E., Balan, V., and Dale, B. E. (2011). "Multi-scale visualization and characterization of lignocellulosic plant cell wall deconstruction during thermochemical pretreatment," Energy Environ. Sci. 4(3), 973-984. 
Fengel, D., and Wegener, G. (1984). Wood. Chemistry, Ultrastructure, Reactions, Walter de Gruyter, Berlin, Germany.

Gao, J., Yang, X., Wan, J., He, Y., Chang, C., Ma, X., and Bai, J. (2016).

"Delignification kinetics of corn stover with aqueous ammonia soaking pretreatment," BioResources 11(1), 2403-2416. DOI: 10.15376/biores.11.1.24032416

Geng, W., Venditti, R., Pawlak, J., and Chang, H-M. (2018). "Effect of delignification on hemicellulose extraction from switch-grass, poplar, and pine and its effect on enzymatic convertibility of cellulose rich residues," BioResources 13(3), 4946-4963. DOI: 10.15376/biores.13.3.4946-4963

Himmelsbach, J. N. (2009). Aqueous Ammonia Soaking (AAS) as a Biomass Pretreatment Method: Pilot-Scale Study with Switchgrass, Bench-Scale Use with Poplar, and Methane Potential from Anaerobic Digestion of Pretreated Switchgrass, Master's Thesis, Iowa University, USA.

Ishizawa, C. I., Davis, M. F., Schell, D. F., and Johnson, D. K. (2007). "Porosity and its effect on the digestibility of dilute sulfuric acid pretreated corn stover," J. Agric. Food Chem. 55(7), 2575-2581.

Kerr, R. A., and Service, R. F. (2005). "What can replace cheap oil—and when?" Science 309, 101.

Kim, T. H., Taylor, F., and Hicks, K. B. (2008). "Bioethanol production from barley hull using SAA (soaking in aqueous ammonia) pretreatment," Bioresource Technol. 99(13), 5694-702. DOI: 10.1016/j.biortech.2007.10.055

Kordala, N., Lewandowska, M., Świątek, M., and Bednarski, W. (2013). “The evaluation of the dependence of the effects of enzymatic hydrolysis of Miscanthus giganteus and rape straw polysaccharides on the conditions of ammonia pretreatment," Acta Sci. Pol. Biotechnol. 12(3), 19-30.

Kumar, R., and Wyman, C. E. (2009). "Effects of cellulase and xylanase enzymes on the deconstruction of solids from pretreatment of poplar by leading technologies," Biotechnol. Prog. 25, 302-314.

Krutul, D. (2002). Exercises in Wood Chemistry and Selected Issues in Organic Chemistry, WULS-SGGW, Warsaw, Poland.

Li, M., Cao, S., Meng, X., Studer, M., Wyman, C. E., Ragauskas, A. J., and Pu, Y. (2017). "The effect of liquid hot water pretreatment on the chemical-structural alteration and the reduced recalcitrance in poplar," Biotechnol. Biofuels 10, 237-249. DOI: 10.1186/s13068-017-0926-6

Radomski, A. (2015). Zastosowanie Odwrotnej Chromatografii Wykluczenia Przestrzennego do Badania Struktury Porowatej Materiałów Lignocelulozowych, WULS-SGGW, Warsaw, Poland.

Saeman, J. F., Moore, W. E., Mitchell, R. L., and Millet, M. A. (1954). "Techniques for the determination of pulp constituents by quantitative paper chromatography," TAPPI 37(8), 336-343.

Striegel, A. M., Yau, W. W., Kirkland, J. J., and Bly, D. D. (2009). Modern sizeexclusion liquid chromatography. Practice of Gel Permeation and Gel Filtration Chromatography, John Wiley \& Sons, Inc, Hoboken, NJ, USA. DOI: 10.1002/9780470442876

Szadkowski, J., and Szadkowska, D. (2020). "The analysis of the distribution of available mesopores in cellulosic pulp, using inverse size exclusion chromatography-ISEC," Annals of WULS - SGGW, Forestry and Wood Technology 109, 103-108. DOI: 
$10.5604 / 01.3001 .0014 .3418$

TAPPI T222 om-02 (2006). "Acid-insoluble lignin in wood and pulp," TAPPI Press, Atlanta, GA.

TAPPI UM 250 (1985). “Acid-soluble lignin in wood and pulp,” TAPPI Press, Atlanta, GA.

Timpa, J. D. (1991). “Application of universal calibration in gel permeation chromatography for molecular weight determinations of plant cell wall polymers; cotton fiber," Journal of Agric. Food Chem. 39, 270-275. DOI: 10.1021/jf00002a010

Verardi, A., De Bari, I., Ricca, E., and Calabrò, V. (2012). "Hydrolysis of lignocellulosic biomass: Current status of processes and technologies and future perspectives," in: Bioethanol, M. A. P. Lima, and A. P. P. Natalense (eds.), InTech, Rijeka, Croatia, DOI: $10.5772 / 23987$

Waliszewska, H., Zborowska, M., Waliszewska, B., Borysiak, S., Antczak, A., and Czekała, W. (2018). "Transformation of miscanthus and sorghum cellulose during methane fermentation,” Cellulose 25, 1207-1216. DOI: 10.1007/s10570-017-1622-1

Wise, L. E., Murphy, M., and Daddieco, A. A. (1946). "Chlorite holocellulose, its fractionation and bearing on summative wood analysis and on studies on the hemicelluloses," Paper Trade J. 122, 35-43.

Yang, B., Dai, Z., Ding, S. Y., and Wyman, C. E. (2011). "Enzymatic hydrolysis of cellulosic biomass," Biofuels 2, 421-450.

Zhu, X., Tang, M., and Chen, H. (2019). "Delignification and hydrolyzation of mycorrhizal black locust biomass pretreated with aqueous ammonia," BioResources 14(1), 965-976. DOI: 10.15376/biores.14.1.965-976

Article submitted: April 16, 2021; Peer review completed: June 13, 2021; Revised version received and accepted: June 19, 2021; Published: June 23, 2021.

DOI: $10.15376 /$ biores.16.3.5618-5627 